Nwaiwu, F. (2018). Review and Comparison of Conceptual Frameworks on Digital Business

Transformation. Journal of Competitiveness, 10(3), 86-100. https://doi.org/10.7441/joc.2018.03.06

\title{
REVIEW AND COMPARISON OF CONCEPTUAL FRAMEWORKS ON DIGITAL BUSINESS TRANSFORMATION
}

\section{- Fortune Nwaiwn}

\begin{abstract}
This paper applies an academic approach in assessing various conceptual and theoretical frameworks considered relevant to the subject of digital business transformation and that contribute to increasing the general understanding of the subject. A review and comparison of several conceptual and theoretical frameworks that were identified to be relevant to the subject of digital business transformation was conducted with the aim of assessing their suitability and robustness in addressing the subject, which is gaining prominence as a pathway for achieving and maintaining competitiveness for businesses as digital technologies continue to shape and transform the business landscape. The background information required for the comparison of the frameworks was obtained after a comprehensive review of each of the frameworks, and based on the insights obtained following the review, their relevance and applicability to the subject of digital business transformation was determined. A qualitative approach was adopted in conducting desk research using reputable business and scientific data sources. The output of the literature search was narrowed down by applying elimination parameters that ensured only relevant articles and journals were included in the final comparison of literatures that contained relevant conceptual and theoretical frameworks. The research established that there is a lack of alignment between industrybased research and academic-based research on the subject of digital business transformation. The research findings and agenda of the study have important implications for organisational transformation as it relates to digital technologies and their transformative effects on industry segments and organisational structures through digitalisation.
\end{abstract}

Keywords: digitisation, digitalisation, digital technologies, digital business transformation, conceptual frameworks, theoretical frameworks

JEL Classification: 032

Received: November, 2017

1st Revision: July, 2018

Accepted: August, 2018

\section{INTRODUCTION}

The emergence of new technologies often leads to significant transformations of society and industry. Recently, the narrative around technology as the key factor for industry transformation 
has largely been framed around the concept of digital business transformation, which also covers how digital technologies are shaping the 4th Industrial Revolution, often referred to as Industry 4.0. The automation of the manufacturing environment through data driven digitisation involves the creation of a digital value chain that facilitates communication between products and their environment and business partners. In contemporary times, the focus has shifted mainly to digital technologies. This is mainly due to the exponential manner in which they are transforming industry. However, their transformative effect goes beyond industry, with their impact also being felt in how markets and customer experience are now being shaped. In a research paper published by the IBM Institute for Business Value in 2017, it was stated that "markets have evolved from organisational centricity, in which manufacturers and service providers largely define what to produce and market to customers; to individual centricity, in which consumers demand insight driven, customised experience; and into a radically different economic environment today" (Berman et al., 2016).

Digital technologies have redefined how people live. Technology is changing traditional industry structures and reinterpreting what it means to be a customer and a citizen (Berman et al., 2016). Within the business and academic environments, the terms digitisation and digitalisation are often used interchangeably such that the distinction between both terms is often blurred. Hence, it is pertinent to properly define them to reduce the chaos often created by diverse views held within industry and academia about digitisation and digitalisation. 'Digitisation' is all about the conversion of analogue information into digital information, while 'digitalisation' refers to the use of digital technologies to change a business model and provide new revenue and value-producing opportunities; it is the process of moving to a digital business (Gartner, 2017).

Kavadia et al. (2016) disagree with the notion that technology is solely responsible for the transformation of industry. They argue that even though new technologies are often major factors, they have never been fully responsible for an industry on their own. Westerman (2017) supports this view, noting that “technology doesn't provide value to a business, but that technology's value comes from doing business differently because technology makes it possible." Therefore, there is a need to look at industry transformation processes more holistically beyond the narrow prism of technology as the main influencing factor. Nevertheless, investigating industry transformation especially in the era of digital technologies requires a theoretical foundation that cuts across industry and academia, that harmonises positions sufficiently with a view to conceptualise and interpret developments within industry as it relates to the impact of digital technologies. This would enable a better understanding of factors that are responsible for industry transformation.

Going beyond the cluster of companies that make up specific industry segments, digital business transformation is of more critical value at the organisational level. Companies are always on the quest for staying ahead of the competitive curve in their bid to remain relevant within their industry segments by achieving sustainable growth. Digital business transformation provides the much needed opportunity through the adoption of digital technologies and adaptation of internal processes such as BPM and Lean Management (Buřita et al., 2018; Chromjaková, 2016; Tuček, 2015), and business models to achieve the much needed flexibility in attaining organisational transformation within the era of the digital economy. Several authors have acknowledged the role and importance of organisational strategy in the quest to achieve digital business transformation (Bharadwaj et al., 2013; Yablonksky, 2018). 
However, there seems to be a lack of consensus on a generally acceptable and sufficiently robust theoretical framework that can help companies and practitioners better understand the process of tracking and achieving digital business transformation within an organisation. Hence, this study reviews and critiques existing conceptual frameworks proposed in both business and academic literature that dwell on digital technologies and digital business transformation, with a view to identify their scope of coverage of the subject and their practical applicability. This paper is organised as follows: a comprehensive review of relevant literature within industry and academia that offer theoretical frameworks for digitisation and digital business transformation. The review will also include literature that explores frameworks that explain the interaction between technology, users, and industry. The paper will then propose a framework based on critiques of existing frameworks in the reviewed literature. The paper will conclude by discussing the applicability of the proposed framework in relation to digital technologies as they are shaping industry 4.0 .

\section{REVIEW OF RELEVANT FRAMEWORKS}

The review of existing conceptual and theoretical frameworks considered relevant to the subject of digital business transformation which in itself is as a consequence of achieving organisational transformation through the adoption of digital technologies and realignment of organisational processes. Also, Schmarzo (2016) views digital business transformation as the process of "integrating the growing body of digital technologies and the resulting customer, product and operational data (insights) into an organization's physical value creation capabilities to yield new sources of intellectual capital (data and analytics), competitive differentiation and customer insight." The following sub-sections review several conceptual and theoretical frameworks considered relevant to the subject of digital business transformation, and technology adoption within the business environment.

\subsection{Six Keys to Success Framework}

The Six keys to success framework proposed by Kavadia et al. (2016) attempts to link technologies and markets, the fundamental premise being that "no new technology can transform an industry unless a business model can link it to an emerging market need." The framework was proposed based on the outcome of in-depth analysis of 40 companies that had launched new business models in different industry segments, and an extensive review of frequently published industry reports by major think-tanks such as PwC, EY, Mckinsey Global Institute, and the Economist Intelligence Unit (EIU).

The six keys employed by the framework in linking technologies to markets are: a more personalised product/service offering, a closed-loop process, asset sharing, usage-based pricing, and a more collaborative ecosystem, an agile and adaptive organisation. Kavadia et al. (2016) views these six keys as the keys to innovation success for any company that intends to successfully digitalise its business model in terms of adopting digital technologies into its core processes, engagement strategies, and value proposition, which in turn may lead to partial or full disruption of an existing market structure. An important point to note about this framework is the hypothesis that "the more of the six features a new business model has, the greater the potential for it to transform a given industry" (Kavadia et al., 2016). 
The findings from the analysis of the 40 companies covered in the study by Kavadia et al. (2016) is closely related with the findings obtained by Bradley et al (2015) in the 'Digital Vortex' framework which shows how companies in various industry segments are being affected by digital disruption, i.e. "it represents the inevitable movement of industries towards a digital centre in which business models and value chains are digitised to the maximum extent" (Bradley et al., 2015). A major shortcoming observed with this framework is that it fails to account for the internal dynamics within companies and organisations that influence its success or failure at achieving a transformative business model that successfully links technology trends to either emerging or established market needs. It fails to account for digital leadership within an organisation which is a function of organisational culture. As noted by Wokurka et al. (2016): "promising business transformations, with expected high business benefits for customers and the organizations, often fail because they collide with the company culture."

\subsection{Digitisation Piano Digital Business Transformation Framework}

Proposed by Wade (2015), it was published in a report by the Global Centre for Digital Business Transformation, and it attempts to explain how successful digital transformation must lead eventually to organisational change, which in turn, should lead to improved performance for the firm through a nexus that connects digital technologies and modern business models. The theoretical premise for this conceptual framework is that: the application of digital technologies with the aim of achieving a successful transformation, must lead to significant organisational transformation which should cover the following areas within the organisation's structure: its business model; its internal structure (how the company is organised); its people (the company's human resource assets); its processes (how the company does things); its ICT capability; its offerings (products or services offered by the company); and lastly, its engagement models (how the company engages with external stakeholders).

The framework is conceptualised in what is described as the "Digital Piano", in which every one of the seven keys represent the areas listed above (see diagram below). The framework was applied to a case that assesses Burberry's efforts at digital business transformation in a ten-year period (2005 - 2015). This framework theoretically adopts a comprehensive firm based approach for looking at digital business transformation because of a company adopting digital technologies; it seems to lack sufficient empirical evidence that rigorously tests its hypothesis when compared to the 'Six Keys to Success' framework. It also focuses exclusively on the firm without having components that assess the impact and influence of external variables which are often beyond the control of the firm. The essence of achieving organisational change through digitalisation is to achieve sustainable growth for the firm, and not just firm transformation or digital disruption of firm's primary market segment. An updated version called the 'Digital Orchestra' framework has been developed to replace the Digital Piano.

\subsection{The Digital Reinvention Framework}

The framework proposed by (Berman et al., 2016) is based on the argument that, "for successful digital reinvention, organisations need to pursue a new strategic focus, build new expertise, and establish new ways of work." It is argued that for traditional organisations to achieve successful 
digital reinvention (which is the same as digital business transformation), they must pursue a fundamental bottom-up reinvention of strategy, operations and technology. Therefore, they should maintain an overarching focus on experience and not on productivity (Berman et al., 2016).

The Digital Reinvention Framework proposes a path to achieving a digitally transformed organisation through an "experience-first" approach that focuses on the adoption of digital drivers (digital technologies such as cloud computing, cognitive and analytics, mobile, Blockchains, IoT, etc.), built on a foundation of three key organisational priorities that are: pursuit of a new focus, development of new expertise, and the establishment of new ways of working. The major limitation observed with the framework is the fact that it still remains purely theoretical without any empirical evidence that tests its hypothesis.

\subsection{Digital Innovation Strategy Framework: for diagnosing and improving digital products and service innovation}

The 'Digital Innovation Strategy' proposed by Nylén \& Holmström (2015) has its major shortcoming in the fact that it focuses exclusively on digital products and services. The focus of the framework leaves out traditional businesses that even though are able to digitalise other segments of the operations and customer engagement, are constrained by the fact that they have to offer products and services that cannot be fully digitised or delivered digitally.

Nevertheless, the framework provides a useful tool that helps organisations offering digital products and services diagnose where they currently are in their journey towards achieving improved digital products and services. The framework focuses on three broad categories: 'Products' - covers user experience, and value proposition; 'Environment' - covers digital evolution scanning; and finally, 'Organisation' - covers skills, and improvisation.

\subsection{Technology Acceptance Model (TAM)}

The Technology Acceptance Model framework was proposed by Davis (1989) there is currently a version 3 of the framework (TAM3). It is premised on the theory that it helps to explain a specific behaviour which in this case is 'usage' towards a specific target, in this case being 'technology', and within a specific context, this could either be 'ease of use' or 'usefulness' as perceived by the user. Venkatesh \& Bala (2008) comment that the TAM framework "posits that individuals' behavioural intention to use an IT is determined by two beliefs: perceived usefulness, defined as the extent to which a person believes that using an IT will enhance his or her job performance and perceived ease of use, defined as the degree to which a person believes that using an IT will be free of effort."

Venkatesh \& Bala (2008) notes that while "the research on individual-level IT adoption and use is mature and has provided rich theories and explanations of the determinants of adoption and use decisions, TAM being a theoretical framework product of one of such research has been shown to be highly predictive of IT adoption and use, one of the major criticism against the model has been its lack of actionable guidance to practitioners." Hence, the need for continuous evolution of the framework to enable it serve as a robust tool for further analysis and understanding of factors that influence adoption and usage of technologies especially ICTs. 
Based on the inadequacies identified for TAM, Venkatesh \& Davis (2000) proposed an update for it, which resulted in development of TAM2 by identifying and theorising about the perceived usefulness - subjective norm, image, job relevance, output quality, result demonstrability; and perceived ease of use - experience and voluntariness. However, the evolution of the TAM still continued with a third update which resulted in TAM3 as proposed by Venkatesh \& Bala (2008), this update was achieved through a combination of TAM2 model of the determinants of perceived ease of use by Venkatesh \& Davis with that of Venkatesh (2000).

TAM3 posits three new relationships that were not empirically tested in TAM2. In TAM3, Venkatesh \& Bala (2008) suggests that "experience will moderate the relationship between the following - perceived ease of use and perceived usefulness; computer anxiety and perceived ease of use; and, perceived ease of use and behavioural intention."

It is acknowledged that TAM and all its derivatives have sufficient empirical evidence to support their viability as robust models that predict user intentions and behaviour towards adoption and use of technologies. However, when considering that in relation to industry 4.0, the adoption and use of digital technologies is from an organisational point of view, it will be understood that predicating digitalisation on the fundamental constructs of perceptions of 'ease of use' and 'usefulness' of digital technologies becomes inadequate to understand the dynamics driving organisational decisions to go the digital route.

\subsection{Digital Transformation Framework, by Corver and Elkhuizen}

The Digital Business Transformation framework proposed by Corver and Elkhuizen (2014) is built on four key items: the customer, product, organisation, and processes and systems. Corver \& Elkhuizen (2014) used the argument that "digital transformation often begins with the customer" as the premise for the framework. Hence, it believes that the process should follow a logical order of getting to know the customers better, then improvements to service levels, followed by digitisation of customer experience, before digital transformation can then be the other three areas which are digitising operations, products and services.

Corver \& Elkhuizen (2014) are of the view that the proposed framework could be useful to organisations in their quest to develop a digital vision and build new business models that are based on digital opportunities. Based on the review of this framework, it may be inferred that a reverse engineering approach is applied in developing this framework as a means to explaining how organisations have successfully transitioned to digitalisation of their business models. This is based on the industry examples cited in the report.

\subsection{Digital Orchestra Framework}

The Digital Orchestra framework was proposed as a replacement for the Digital Piano framework. The framework was published in a report by the Global Centre for Digital Business Transformation - (GCDBM) - an initiative by IMD and Cisco Corporation. The underpinning basis for the framework is that an organisation's leadership must determine what type of value they want to create, and decide the strategic options for achieving it. The framework captures ten areas an organisation should consider during a digital transformation (Wade et al, 2017). The areas are as follows: Offerings, Channels (Go-to-Market); Customers, Partners, Workforce (Engagement); Processes, IT Capability (Operations); and Structures, Incentives, Culture (Organisation). 
The framework offers significant coverage of organisational structure and interests such that it presents a valuable tool for coordinating the reinvention of an organisational through digitalisation. The four groupings of operating models which covers the ten items within the framework works in a manner that makes it mandatory for them to join forces seamlessly in the digital business transformation journey of any organisation that decides to adopt the framework as a guide. This is the updated framework that replaced the Digital Piano originally proposed for assessing digital business transformation within a company.

\subsection{Digital Transformation Framework, by Matt et al.}

Digital Transformation Framework is another framework that seeks to address the subject of understanding the dynamics of digital transformation within an organisation. Matt et al. (2015) while proposing this framework, premised it on the idea that the digital transformation of an organisation must serve as a central concept that would integrate the entire coordination, prioritisation and implementation of digitalisation within the organisation. Hence, Matt et al. (2015) argues that "digital transformation strategies should encompass four essential dimensions: use of technologies, changes in value creation, structured changes, and financial aspects." The financial aspect is at the core of this model, it serves as the primary driver and motivation which is a unique approach at proposing a framework for understanding the dynamics of digital transformation of a business entity, considering that an organisation's strategic focus is primary on sustainable growth and profit in the long run.

The framework lays a basic academic foundation for understanding digitalisation by describing building blocks for digital transformation along four dimensions which it considers to be important. The authors suggest future research that should be aimed at identifying and concretizing common elements that can be linked to the four proposed dimensions that form the cornerstone of the framework. It is pertinent to note that while this framework was proposed and developed within the academia, it is yet to be tested or validated as a rigorous framework that can be applied in understanding digitalisation. Hence, it still remains in the conceptual stage of development.

\subsection{Digital Enterprise Integrative Management Framework}

Bowersox et al. (2005) proposed the Digital Enterprise Integrative Management framework from a supply chain excellence perspective; they argued that "true supply chain excellence can only be achieved through digital business transformation." Bowersox et al. (2005) consider it a transformation that exploits all the capabilities technology has to offer, which in turn facilitates supply chain collaboration, and leads to new levels of operational excellence. Hence, their framework tries to link the achievement of 'true collaboration' within a supply chain with digital business transformation as a precondition for true collaboration to occur.

Their framework adopts an approach of breaking the transformation into three processes: Enterprise core processes - focused on the maximisation of customer value; shared real-time information and operational connectivity - this creates a response-based/demand-driven network of supply chain relationships among participating business entities; and, a commitment to operational excellence - manifested in the form of customer centricity (Bowersox et al., 2005). It is pertinent to note that their framework recognises the supply chain as an ecosystem of multiple 
enterprises who are stakeholders and participants all focused on one objective which is achieving and maintaining customer centricity.

The Enterprise core processes aspect of the framework is at the heart of the framework, it takes the traditional organisation and transforms it into an integrated enterprise with five component parts: integrated operations, measurement and metrics, financial stewardship, customer accommodation, and human resource development. The framework does a good job from an academic point of view in outlining a 'how to' approach of achieving digital business transformation with its 'Six Fs' of going digital recommendations. However, like most of the other conceptual frameworks reviewed so far, it falls short on being a validated and rigorously tested framework with no empirical evidence to support its practicability.

\subsection{The Unified Theory of Acceptance and Use of Technology (UTAUT) Framework}

Venkatesh et al. (2003) proposed and developed the Unified Theory of Acceptance and Use of Technology (UTAUT), the framework was developed through a review and consolidation of the constructs contained in eight prominent theories previously employed by researchers in explaining ICT usage behaviour: UTAUT incorporated TAM, Theory of planned behaviour (TPB), innovation diffusion theory (IDT), motivation model, social cognitive theory to develop a unified theory for technology acceptance (Negahban \& Chung, 2014). The model proposes four constructs namely (i) performance expectancy, (ii) effort expectancy, (iii) social influence, and (iv) facilitating conditions, grouping similar earlier constructs (Venkatesh et. al., 2003 as cited in Baptista \& Oliveira, 2015). UTAUT correlates environmental, social, and economic factors directly to the behavioural change of business. It suggests that businesses are likely to adopt, accept and use a certain piece of technology or technologies if these three factors are present.

There has been a growing interest among researchers in using the UTAUT framework, finding application in diverse areas of research interests such as in exploring user acceptance of mobile technologies, to several technologies for both individual and organizational. The UTAUT model has been useful in explaining a large portion of variance in behavioural intention towards the use of technology. However, one interesting observation about the model is that, based on cross-cultural examination of the model, empirical evidence shows that it responds to the growing needs of understanding factors that are critical to success of IT deployment in a business environment (Venkatesh \& Zhang, 2010).

\section{REVIEW METHODOLOGY}

The research adopted a qualitative approach, which involved extensive desk research and review of relevant business and academic literature on the subjects of 'Digitalisation', 'Digital Business Transformation', and 'Technology use behaviours'. The desk research utilised prominent web based journal sources such as Google Scholar and Scopus to ensure extensive coverage of publications in other databases. The following criteria were applied in the search and selection of papers covered in the study: the keywords - digitisation, digitalisation, technology adoption, technology use behaviour, conceptual frameworks, theoretical frameworks were used to search 
the titles and abstracts of the publications; the next step involved the elimination of unpublished working papers, masters/doctoral theses, and textbooks. However, an exception was made for industry publications due to the limited output generated based on search criteria from the academia; finally, after the first two criteria were applied to filter the output, the remaining journal publications that were available in English were all considered (without strict considerations to only those that were peer-reviewed, already published, or still in press). This exemption rule was important considering that most business publications on the subject matter were not peer-reviewed.

The search yielded 40 related publications published between 1989 and 2017. The next step was to carefully study the full text of these publications and only those that offered some form of conceptual or theoretical framework that explored the research focus were included in the review and comparison. The factors applied in comparing the various conceptual and theoretical frameworks contained in identified literatures were as follows: "Assess current state of digitisation" - looks at if the model under review is useful in determining the current state of digital business transformation in an organisation; "what to transform" - consists of three sub-groups which looks at number of items based on an organisation's structure that the model recommends to be transformed, the next sub-group of list of items offers a list of the items the model recommends to be transformed, and finally, the third sub-group questions whether what the model recommends to be transformed is detailed or not; "how to transform" - it also has two subgroups, first being the actions to be taken as recommended by the model, and the second also questions if the actions as recommended by the model is detailed or not; the final factor applied in the comparison questions if the model is scientifically validated or not; "origin of framework" - either business or academia; and finally, "framework scientifically validated" - this factor identifies if the framework has been subjected to the rigours of scientific validation or not.

\section{COMPARISON OF FRAMEWORKS}

This section compares the reviewed conceptual frameworks on the basis of their applicability to a scenario of digitalisation in industry. The comparison adopts several parameters in assessing the various conceptual frameworks. The parameters used in assessing the reviewed conceptual frameworks was based the following criteria: their ability to help organisations understand where they currently are positioned in their digital transformation journey, their ability to help organisations understand what needs to be transformed; and finally, their ability to help organisations understand how they can achieve digital transformation.

The table below presents a summary of the comparison of various frameworks both within industry and academia based on an extensive review. It is pertinent to note that an overwhelming number of conceptual frameworks on digitalisation have their roots in industry publication, and academia offers nothing except for the TAM, which cannot be expressly taken as a framework for digitalisation. Quite ironically, only the TAM framework has been subjected to academic validation when compared to the rest as a scientifically rigorous framework backed by theory. The models were compared via their ability to assess the current state of digital transformation within an organisation. Based on this parameter, only three of the six frameworks reviewed 
have the capability to help an organisation understand their current position in the digital transformation journey - the Six Keys to Success, Digital Piano, and Digital Innovation Strategy frameworks. The next parameter that was considered focuses on 'what to transform' within the organisation; for this parameter, the Digital Piano framework provides the most comprehensive coverage with seven areas suggested for the organisation, while the TAM3 framework has the least with zero areas suggested. The Six Keys to Success quite remarkably only focuses on the business model as the area to cover, but does this by linking technologies identified with market opportunities. This makes the framework more of a diagnostic tool than a 'how to' tool. The final parameter considered is the 'how to transform' parameter. For this parameter, only two - the Digital Innovation Strategy and TAM3 - fail to provide a minimum guide on how organisations can achieve digital business transformation. Also, none of the frameworks reviewed so far offer any detailed approach on how to achieve digital business transformation.

Tab. 1 - Comparison of relevant conceptual and theoretical frameworks. Source: self-attribution

\begin{tabular}{|c|c|c|c|c|c|c|c|c|}
\hline 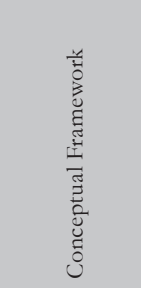 & 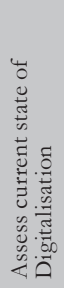 & 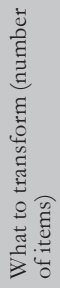 &  & 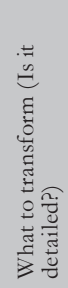 &  & 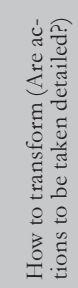 & 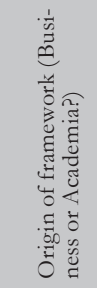 & 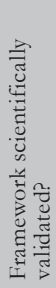 \\
\hline $\begin{array}{l}\text { Six Keys to } \\
\text { Success }\end{array}$ & Yes & 1 & Business model & Yes & $\begin{array}{l}\text { By linking technol- } \\
\text { ogy trends to market } \\
\text { needs }\end{array}$ & No & Business & No \\
\hline $\begin{array}{l}\text { Digitisation } \\
\text { Piano }\end{array}$ & Yes & 7 & $\begin{array}{l}\text { Business Model, Or- } \\
\text { ganisation structure, } \\
\text { Human resources, } \\
\text { Internal processes, IT } \\
\text { capabilities, Products/ } \\
\text { Services, Stakeholders } \\
\text { engagement }\end{array}$ & Yes & $\begin{array}{l}\text { Process of dig- } \\
\text { ital transformation } \\
\text { should lead to } \\
\text { organisational change } \\
\text { and development } \\
\text { of digital business } \\
\text { agility }\end{array}$ & No & Business & No \\
\hline $\begin{array}{l}\text { Digital } \\
\text { Orchestra }\end{array}$ & No & 10 & $\begin{array}{l}\text { Offerings, Channels } \\
\text { (Go-to-Market); } \\
\text { Customers, Partners, } \\
\text { Workforce (Engage- } \\
\text { ment); Processes, IT } \\
\text { Capability (Opera- } \\
\text { tions); and Structures, } \\
\text { Incentives, Culture } \\
\text { (Organisation) }\end{array}$ & Yes & $\begin{array}{l}\text { Organisation's } \\
\text { leadership must } \\
\text { determine what type } \\
\text { of value they want to } \\
\text { create, and decide the } \\
\text { strategic options for } \\
\text { achieving it }\end{array}$ & Yes & Business & No \\
\hline $\begin{array}{l}\text { Digital Rein- } \\
\text { vention }\end{array}$ & No & 3 & $\begin{array}{l}\text { New Expertise } \\
\text { (human resources, } \\
\text { orchestrated eco- } \\
\text { system), New Focus } \\
\text { (business models, } \\
\text { market/customer } \\
\text { activation), New Ways } \\
\text { to Work (responsive } \\
\text { operations, actionable } \\
\text { insights) }\end{array}$ & No & $\begin{array}{l}\text { To achieve digital } \\
\text { reinvention, organisa- } \\
\text { tions must pursue a } \\
\text { bottom-up reinven- } \\
\text { tion of strategy }\end{array}$ & No & Business & No \\
\hline
\end{tabular}




\begin{tabular}{|c|c|c|c|c|c|c|c|c|}
\hline $\begin{array}{l}\text { Digital } \\
\text { Innovation } \\
\text { Strategy } \\
\text { (digital goods } \\
\text { and services } \\
\text { only) }\end{array}$ & Yes & 3 & $\begin{array}{l}\text { Product (user experi- } \\
\text { ence, value proposi- } \\
\text { tion), Environment } \\
\text { (digital evolution } \\
\text { scanning), Organisa- } \\
\text { tion (skills/human } \\
\text { resources, improvisa- } \\
\text { tion) }\end{array}$ & Yes & $\begin{array}{l}\text { No specific strat- } \\
\text { egy direction is } \\
\text { suggested, framework } \\
\text { is focused exclusively } \\
\text { on digital products/ } \\
\text { services }\end{array}$ & No & Academia & No \\
\hline $\begin{array}{l}\text { Technology } \\
\text { Acceptance } \\
\text { Model } 3 \\
\text { (TAM3) }\end{array}$ & No & 0 & $\begin{array}{l}\text { No specific item(s) } \\
\text { listed by this frame- } \\
\text { work }\end{array}$ & No & $\begin{array}{l}\text { No specific strat- } \\
\text { egy direction is } \\
\text { suggested, framework } \\
\text { seeks to understand } \\
\text { technology adoption } \\
\text { from a 'person' point } \\
\text { of view. }\end{array}$ & No & Academia & Yes \\
\hline $\begin{array}{l}\text { Digital Trans- } \\
\text { formation } \\
\text { Framework } \\
\text { by Corver } \\
\text { and Elkhui- } \\
\text { zen }\end{array}$ & No & 4 & $\begin{array}{l}\text { Customer, Product, } \\
\text { Organisation, Proc- } \\
\text { esses and Systems }\end{array}$ & Yes & $\begin{array}{l}\text { Digital transforma- } \\
\text { tion should be with } \\
\text { understanding the } \\
\text { customer, then move } \\
\text { to cover the three } \\
\text { other areas }\end{array}$ & No & Business & No \\
\hline $\begin{array}{l}\text { Digital Trans- } \\
\text { formation } \\
\text { Framework } \\
\text { by Matt et al. }\end{array}$ & No & 4 & $\begin{array}{l}\text { User of technolo- } \\
\text { gies, Change in value } \\
\text { creation, Structural } \\
\text { changes, financial } \\
\text { aspects }\end{array}$ & No & $\begin{array}{l}\text { Digital transforma- } \\
\text { tion should serve } \\
\text { as a central concept } \\
\text { to integrate the } \\
\text { entire coordination, } \\
\text { privatisation and } \\
\text { implementation of } \\
\text { digitalisation. }\end{array}$ & No & Academia & No \\
\hline $\begin{array}{l}\text { Digital } \\
\text { Enterprise } \\
\text { Integrated } \\
\text { Management } \\
\text { Framework }\end{array}$ & No & 5 & $\begin{array}{l}\text { Financial stewardship, } \\
\text { Integrated operations, } \\
\text { Customer accommo- } \\
\text { dation, Measurement } \\
\text { and metrics, Human } \\
\text { resources develop- } \\
\text { ment }\end{array}$ & Yes & $\begin{array}{l}\text { By linking the } \\
\text { achievement of 'true } \\
\text { collaboration' within } \\
\text { a supply chain with } \\
\text { digital business trans- } \\
\text { formation }\end{array}$ & Yes & Academia & No \\
\hline $\begin{array}{l}\text { The Unified } \\
\text { Theory of } \\
\text { Acceptance } \\
\text { and Use of } \\
\text { Technology } 2 \\
\text { (UTAUT2) }\end{array}$ & No & 0 & $\begin{array}{l}\text { No specific item(s) } \\
\text { listed by this frame- } \\
\text { work }\end{array}$ & No & $\begin{array}{l}\text { No specific strat- } \\
\text { egy direction is } \\
\text { suggested, framework } \\
\text { seeks to understand } \\
\text { technology adoption } \\
\text { from a 'person' point } \\
\text { of view. }\end{array}$ & No & Academia & Yes \\
\hline
\end{tabular}

\section{CONCLUSIONS AND RECOMMENDATIONS}

After the literature review, ten frameworks were identified as relevant to the subjects of digital business transformation and digital technologies in industry. It was observed that the more relevant frameworks that addressed the issue of digital business transformation directly had their origins in business publications, while those in academia more inclined towards technology adoption and the use behaviour of persons, even though a few attempts had been made to apply them from an organisational point of view.

Frameworks with academic origins that look at technology adoption from a 'person' point of view seem to lack the depth required to understand how different industry segments are being shaped and transformed by digitisation and digitalisation. This shortcoming is significant 
because digital business transformation is more an organisational strategy issue than one that deals with technology adoption and use behaviour. Hence, TAM and UTAUT as theoretical frameworks may require significant modifications that would enable them to become more robust analytic tools capable of handling the requirements of digital technologies, their industry impact and organisational strategy. The constructs covered by most of the business-originated frameworks such as human resource issues, customer engagement/centricity, and agility, reveal the limits of academic frameworks in understanding digital business transformation.

Among the business-originated frameworks, the Six Keys to Success framework stands out, as it jumps right into a useful segment and carves out a niche for itself by its unique approach of directly attempting to link technology trends to market opportunities. It does so without entangling itself with organisational structure and strategy issues. Hence, it speaks directly to digitalisation from an Industry 4.0 perspective where it can be useful in suggesting how digital technologies can be practically applied in enhancing processes and improving the overall competitiveness of a company within its industry segment. However, the other business-originated frameworks address the issue of digital business transformation holistically by approaching the subject using the organisational structure and other internal/external factors in addressing the subject of digitalisation.

It was observed from most of the business-originated frameworks reviewed that there is an overlap of constructs captured by these frameworks. For example, the issue of human resources was captured by the following frameworks: Digitisation Piano, Digital Reinvention, Digital Innovation Strategy, Digital Transformation, Digital Orchestra, and the Digital Enterprise Integrative Management frameworks; another construct that was captured by multiple business-originated frameworks was that related to the customer. These overlaps are significant because they show agreement among those responsible for developing these frameworks on factors that should be of interest for digital business transformation to be successful within an organisation.

The result of the reviews and comparison contained in the research showed a clear disconnect between business research interests on digital business transformation and what is currently obtainable in academia. It raises important questions, which could serve as a basis for future research: why is business running tangential to academia on the subject of digital business transformation? Is output from academia not supposed to drive business? In addition, should there not be a merger/alignment of research interests in the subject matter?

Organisations today understand the usefulness of technology and why they need to achieve the organisational transformation through adoption and incorporation of digital technologies into their business processes to improve process efficiency and create new revenue generating streams. It is also acknowledged that there is not yet any empirical evidence that can be referred to in determining the impact of perceptions of 'ease of use' in influencing the decisions of organisations to adopt digital technologies. The focus here is on digitalisation, which is more about digital reinvention or transformation of an organisation and not about purely an issue of adoption of technology. Taking this into account, it can be posited that theoretically validated frameworks such as the TAM, UTAUT and their variants are inadequate to fully understand the dynamics of digitalisation and digital business transformation. Hence, the need for an alternative framework that would serve as a basis for a better understanding of digitalisation. 
Finally, considering that the issue of digital business transformation is still in an evolutionary stage, and the need for a high degree of contextualisation is often encountered in implementing digital business transformation within a company, and the various frameworks available, the choice of framework to be adopted within an organisation should be carefully thought through, and factors such as the current state of digital transformation within the company's industry segment, it's corporate strategy focus, and vision and mission should be considered in deciding which model to use in guiding its digital transformation/reinvention. There is not a one size fits all model that can serve for all digital business transformation journeys. Some unique cases may require a combination of models depending on the extant context within the organisation.

\section{ACKNOWLEDGEMENTS}

This study was supported by funding provided by IGA/FaME/2018/005 - "Process management model proposal for implementation of Industry 4.0 in SMEs."

\section{References}

1. Baptista, G., \& Oliveira, T. (2015). Understanding mobile banking: The unified theory of acceptance and use of technology combined with cultural moderators. Computers in Human Behaviour, vol 50, pp: 418-430. https://doi.org/10.1016/j.chb.2015.04.024

2. Berman, S., Korsten, P., \& Marshall, A. (2016). Digital Reinvention in Action: What to Do and How to Make It Happen. IBM, 2016. Retrieved from http://public.dhe.ibm.com/common/ssi/ecm/ gb/en/gbe03752usen/gbe03752-usen-08_GBE03752USEN.pdf

3. Bharadwaj, A., El Sawy, O.A., Pavlou, P.A., \& Venkatraman, N. Digital business strategy: toward a next generation of insights. MIS Quarterly, 37 (2), 471-482.

4. Bowersox, D. J., Closs, D. J., \& Drayer, R. W. (2005). The Digital Transformation: Technology and beyond. Supply Chain Management Review, 9 (1), 22-29. Retrieved from https://search. proquest.com/docview/221201326?accountid=15518

5. Bradley, J., Loucks, J., Macaulay, J., Noronha, A., \& Wade, M. (2015). Digital Vortex: How Digital Disruption Is Redefining Industries. Cisco. Retrieved from https://www.cisco.com/c/ $\mathrm{dam} / \mathrm{en} / \mathrm{us} /$ solutions/collateral/industry-solutions/digital-vortex-report.pdf.

6. Buřita L., Hrušecká D., Pivnička M., \& Rosman P. (2018). The use of knowledge management systems and event-B modelling in a lean enterpise. Journal of Competitiveness, 10 (1), 40-53. https://doi.org/10.7441/joc.2018.01.03

7. Corver, Q., \& Elkhuizen, G. (2014). A Framework for Digital Business Transformation. Cognizant, 1-10. Retrieved from https://www.cognizant.com/InsightsWhitepapers/aframework-for-digital-business-transformation-codex-1048.pdf

8. Chromjaková F. (2016). The Key Principles of Process Manager Motivation in Production and Administration Processes in an Industrial Enterprise. Journal of Competitiveness, 8 (1), 95110 https://doi.org/10.7441/joc.2016.01.07

9. Davis, F. (1989). Perceived usefulness, perceived ease of use, and user acceptance of information technology. MIS Quarterly, 13 (3), 319-340. https://doi.org/10.2307/249008

10. Kavadias, S., Ladas, K., \& Loch, C. (2016). The transformative business model. Harvard Business Review, 1. Retrieved from https://search.proquest.com/docview/ 1827622937 ? accountid $=15518$ 
11. Matt, C., Hess, T., \& Benlian, A. (2015). Digital Transformation Strategies. Business \& Information Systems Engineering, 57 (5). 339-343. https://doi.org/10.1007/s12599-015-0401-5

12. Negahban, A., \& Chung, C. H. (2014). Discovering determinants of users perception of mobile device functionality fit. Computers in Human Behaviour. 35 (1), 75-84. https://doi. org/10.1016/J.CHB.2014.02.020

13. Nylén, D. \& Holmström, J. (2015). Digital innovation strategy: A framework for diagnosing and improving digital product and service innovation. Business Horizons, 58 (1), 57-67. https:// doi.org/10.1016/j.bushor.2014.09.001

14. Schmarzo, B. (2016). Digital Business Transformation Framework, CIO from IDG. Retrieved from https://www.cio.com/article/3130103/analytics/digital-business-transformationframework.html

15. Tuček D. (2015). The Main Reasons for Implementing BPM in Czech Companies. Journal of Competitiveness, 7 (3), 126-142 https://doi.org/10.7441/joc.2015.03.09

16. Venkatesh, V., \& Bala, H. (2008). Technology Acceptance Model 3 and a Research Agenda on Interventions Subject Areas: Design Characteristics, Interventions, Management Sup- port, Organizational Support, Peer Support, Technology Acceptance Model (TAM), Technology Adoption, Training, User Acceptance, User Involvement, and User Participation. Decision Sciences, 39 (2).

17. Venkatesh, V., \& Davis, F.D. (2000). A Theoretical Extension of the Technology Acceptance Model: Four Longitudinal Field Studies. Management Science, 46 (2), 186-204. https://doi. org $/ 10.1287 /$ mnsc.46.2.186.11926

18. Venkatesh, V. (2000). Determinants of Perceived Ease of Use: Integrating Control, Intrinsic Motivation, and Emotion into the Technology Acceptance Model. Information Systems Reserach, 11 (4), 342-365. https://doi.org/10.1287/isre.11.4.342.11872

19. Venkatesh, V., Morris, M. G., Davis, G. B., \& Davis, F. D. (2003). User Acceptance of Information Technology: Toward a unified view. MIS Quarterly, 27 (3). 425-478. https://doi. org/10.1017/CBO9781107415324.004

20. Venkatesh, f. \& Zhang X. (2010). Unified theory of acceptance and use of technology: US vs. China. Journal of Global Informantion Technology Management, 13 (1), 5-27. https://doi.org/ 10.1080/1097198X.2010.10856507

21. Wade, M., Noronha, A., Macaulay, J., \& Barbier, J. (2017). Orchestrating digital business transformation. Working in Concert to Achieve Digital Excellence.

22. Wade, M. (2015). Digital Business Transformation.

23. Westerman, G. (2017). Your Company Doesn't Need a Digital Strategy. MITSloan Management Review. Retrieved from https://sloanreview.mit.edu/article/your-company-doesnt-need-adigital-strategy/.

24. Wokurka G., Banschbach Y., Houlder D., \& Jolly R. (2017) Digital Culture: Why Strategy and Culture Should Eat Breakfast Together. In: Oswald G., Kleinemeier M. (eds) Shaping the Digital Enterprise. Springer, Cham

25. Yablonsky, S. (2018) A Multidimensional Framework for Digital Platform Innovation and Management: From Business to Technological Platforms. System Research and Behavioral Sciences, 
35: 485-501. https://doi.org/10.1002/sres.2544

\section{Contact information}

Ing. Fortune Nwaiwn

Tomas Bata University in Zlin

Faculty of Management and Economics

Department of Industrial Engineering

Crech Republic

E-mail:nwaiwu@utb.cz.

ORCID: 0000-0001-8900-2130 